\title{
Perichondrium - An Autologous Substitute for Temporalis Fascia in Type I Tympanoplasty: A Comparative Study
}

\author{
Bahnisikha Kayet, ${ }^{1}$ Arya Brata Dubey ${ }^{1}$
}

\section{Introduction:}

\section{$\underline{\text { ABSTRACT }}$}

Temporalis fascia is the commonly used graft material for tympanic membrane reconstruction. Tragal perichondrium share with the fascia the quality of being mesenchymal tissue. In our study we compared perichondrium and temporalis fascia in terms of graft uptake and hearing improvement.

Materials and Methods:

All patients presenting with discharge from ear and decreased hearing were subjected to clinical examination and investigation. Patients satisfying inclusion criteria were included in study with total of 40 patients. Twenty underwent typel tympanoplasty with temporalis fascia (TF) and another 20 patients with tragal perichondrium (TP). To evaluate success patients are evaluated at end of 6 months for graft uptake and 3 months for hearing results in audiological gain of $10 \mathrm{~dB}$ in two consecutive frequencies. Results:

Mean Pre-op AC Threshold in TF group was $30.75 \mathrm{~dB} \pm 5.16$ and Post-op AC Threshold was 14.15 dB \pm 8.05 . Mean Pre-op AC Threshold in TP group was $32.2 \mathrm{~dB} \pm 4.81$ and Post-op AC Threshold was $20.95 \mathrm{~dB} \pm 7.14$. Mean post-op AC Threshold, Mean Post-Op AB Gap and Mean Audiological Gain was statistically significant among 2 groups $p=0.0075, p=0.0013, p=0.0294$ respectively. Temporalis fascia was better than Tragal Perichondrium. Graft uptake in 2 groups was not significant $(p=0.6325)$. Conclusion:

From the present study we may conclude that temporalis fascia, tragal perichondrium free grafts provide viable autograft material for tympanoplasty. Both achieve good hearing restoration but the improvement in hearing or audiological gain is better in temporalis fascia graft than in tragal perichondrium graft.

Keywords:

Tympanoplasty; Autografts; Fascia; Perichondrium

$\mathrm{T}$ The tympanic membrane (TM) plays a significant role in the physiology of hearing as well as in the pathophysiology of chronic inflammatory middle ear diseases. Infection, acute or chronic, is the principal cause of TM perforation. Majority of post acute infection and traumatic TM perforations however heal spontaneously or with conservative treatment. If the perforations fail to heal conservatively they require surgical closure. The repaired perforation restores vibratory area and restores round window protection, thus improving hearing. It also prevents exposure of the middle ear to external infections. There are a number of materials for closure of TM perforations like skin $^{1}$ perichondrium, $, 2,3$ vein, ${ }^{4}$ temporalis fascia,${ }^{5}$ dura,${ }^{6}$ cartilage. . $^{7,9,9,10}$

Biological graft material acts as a scaffold of tissue matrix when applied to seal the perforation. Such abundance of material imply graft selection depends upon surgeon's choice. Temporalis fascia is the commonly used graft material for tympanic membrane reconstruction, because it is an autograft with excellent chance of take up, available close to the site of operation making its harvesting easier, a low basal metabolic rate, increased success rate, and its thickness is more or less similar to that of tympanic membrane. Tragal perichondrium shares with the fascia the quality of

1 - Institute of Post-Graduate Medical Education \&

Research,Kolkata

Corresponding author:

Dr Arya Brata Dubey

email: dubey.arya9@gmail.com 


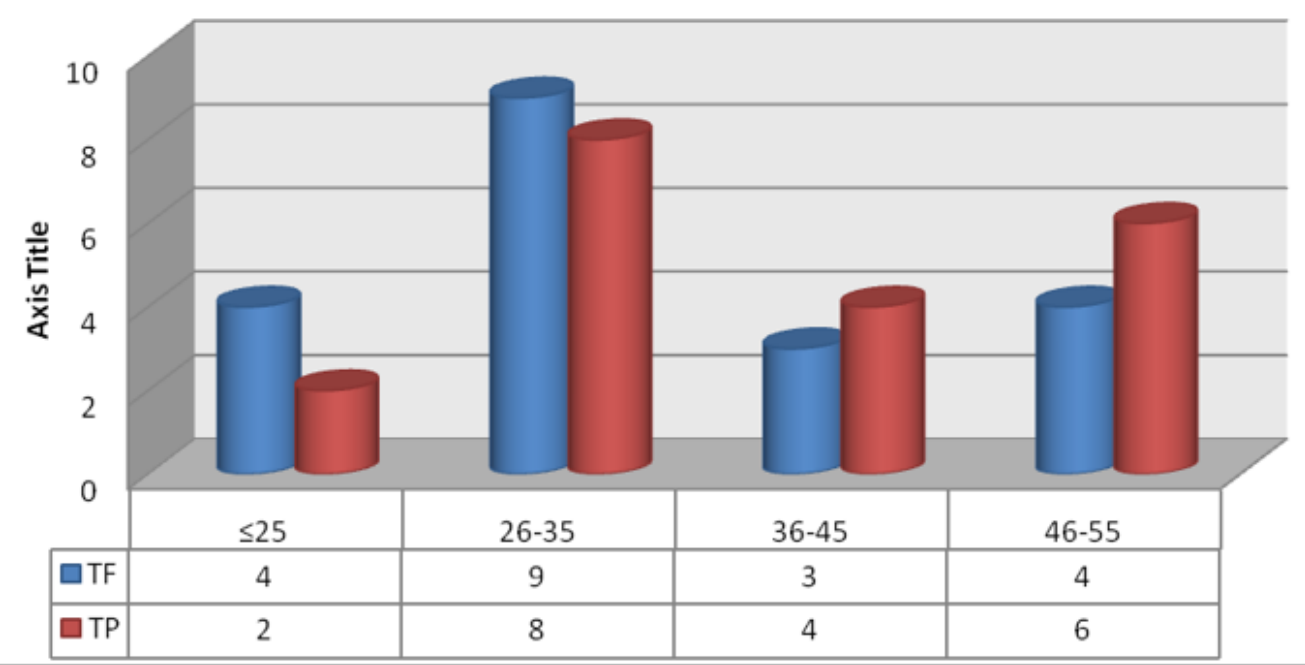

Fig 1. Age wise distribution of two groups. (TF- Temporalis Fascia; TP- Tragal Perichondrium)

being mesenchymal tissue ${ }^{11}$ but it is thicker and stiffer. It is also easily harvested with small incision on inner surface of tragus with an inconspicuous scar.

This study compared perichondrium and temporalis fascia in terms of graft uptake and hearing improvement.

\section{Materials and Methods}

All the patients attending our OPD with history of discharge per ear and decreased hearing were subjected to detailed clinical history taking clinical examination. Patients between $15-55$ years of age with central/subtotal perforation of the tympanic membrane and mild to moderate conductive hearing loss were included in the study. Patients with evidence of cholesteatoma, having previous history of surgery, pre-existing/congenital hearing loss, known eustachian tube dysfunction or any associated pathology and active infection in ear, nose, throat and paranasal sinuses were excluded from this study. Patient having ossicular discontinuity/ fixation, abnormality in the external ear canal or patients suffering from diabetes, malignancy and other debilitating diseases were also excluded.

Patients were alternately selected from study population until a sample size of 40 patients was reached. 20 patients of them undergone type 1 tympanoplasty with temporalis fascia (Group TF) and another 20 patients with tragal perichondrium (Group TP).

To evaluate success patients are evaluated at end of 6 months for graft uptake and 3 months for hearing results in audiological gain of $10 \mathrm{~dB}$ in two consecutive frequencies.

\section{Surgical Procedure:}

Patients underwent surgery under local anaesthesia. Intravenous antibiotic (Cefotaxime or Ceftriaxone sodium) was given 30 minutes prior to the surgery.

Combination of Inj. Pethidine $75 \mathrm{mg}$ and Promethazine $25 \mathrm{mg}$ (Phenergan) was given 30 minutes prior to the surgery. 2\% Lignocaine with 1: 100000 Adrenaline was used for infiltration in tragus, post-auricular and 4 quadrants of external auditory canal.

All patients were operated through postaural approach. The temporalis fascia was harvested through same incision. For the tragal perichondrial graft, an incision was made $2 \mathrm{~mm}$ medial from the tragal crest line. The tragal cartilage was removed by cutting through the areolar tissue. The perichondrium was dissected in continuity from both surfaces of the excised cartilage. The cartilage was replaced in its skin pocket and the incision closed. The margin of perforation freshened and undersurface of TM scraped. The tympanomeatal flap elevated and middle ear entered. Ossicular intactness 
Table I: Sex distribution among the two groups

\begin{tabular}{|c|c|c|c|}
\hline \multirow{2}{*}{ SEX } & \multicolumn{3}{|c|}{ GROUP } \\
\cline { 2 - 4 } & TF & TP & TOTAL \\
\hline Male & $10(45.5 \%)$ & $12(54.5 \%)$ & $22(55 \%)$ \\
\hline Female & $10(55.6 \%)$ & $\mathbf{8}(44.4 \%)$ & $18(45 \%)$ \\
\hline Total & 20 & 20 & 40 \\
\hline
\end{tabular}

Table II: OT laterality of 2 groups.

\begin{tabular}{|c|c|c|c|}
\hline \multirow{2}{*}{ OT SIDE } & \multicolumn{3}{|c|}{ GROUP } \\
\cline { 2 - 4 } & TF & TP & TOTAL \\
\hline LEFT & $12(60 \%)$ & $\mathbf{8}(40 \%)$ & $20(50 \%)$ \\
\hline RIGHT & $\mathbf{8}(40 \%)$ & $\mathbf{1 2}(60 \%)$ & $20(50 \%)$ \\
\hline TOTAL & 20 & 20 & 40 \\
\hline
\end{tabular}

Table III: Duration of symptoms among 2 groups.

\begin{tabular}{|c|c|c|c|c|c|c|c|}
\hline GROUP & NUMBER & MEAN & SD & MINIMUM & MAXIMUM & MEDIAN & P-VALUE \\
\hline TF & 20 & 13.4 & 6.49 & 6 & 24 & 11 & 0.8003 \\
\hline TP & 20 & 13.9 & 5.91 & 5 & 24 & 13 & \\
\hline
\end{tabular}

and mobility confirmed. The graft was placed medial to the handle of malleus in underlay technique. The middle ear cavity is packed with gel foam to support the fascia graft. After repositioning the TM flap antibioticsoaked gelfoam pieces placed in the external canal to stabilize the graft. Post operatively the patients were put on a course of antibiotic, analgesics, antihistamines and decongestant nasal drops. Mastoid bandage and dressings were removed next day of operation (24-48 hrs). Stitches were removed after 6-7 days later. Patients were discharged after 2 days. Patients were called up for first follow up at the end of 1 st week post operatively, then at three weekly imterval upto 6 months.

Statistical Analysis was done using appropriate test for various outcomes. Student's independent sample's t-test was applied to compare normally distributed numerical variables between groups, Unpaired proportions were compared by Chi-square test or Fischer's exact test, as appropriate. The p-value $<0.05$ was considered significant.

\section{Results}

Most of the patients are in the age group of 26-35 yrs. (Fig.1) The mean age in Group TF is $33.95 \pm 10.86$ years and Group TP is $36.75 \pm 11.52$ ( p-value=0.4340)

In TF group, $10(50.0 \%)$ patients were female and 10 (50.0\%) patients were male. In TP group, 12(60.0\%) patients were female and $8(40.0 \%)$ patients were male. This distribution was not statistically significant $(\mathrm{p}=0.5250)$. (Table I)

Laterality distribution of two groups was not statistically significant $(\mathrm{p}=0.2059)$. (Table II)

In Group TF, the mean duration of symptoms (mean \pm $\mathrm{SD})$ of patients was $13.40 \pm 6.49$ months. In Group TP, the mean duration of symptoms (mean $\pm \mathrm{SD}$ ) of patients was $13.90 \pm 5.91$ months. Difference of mean duration 


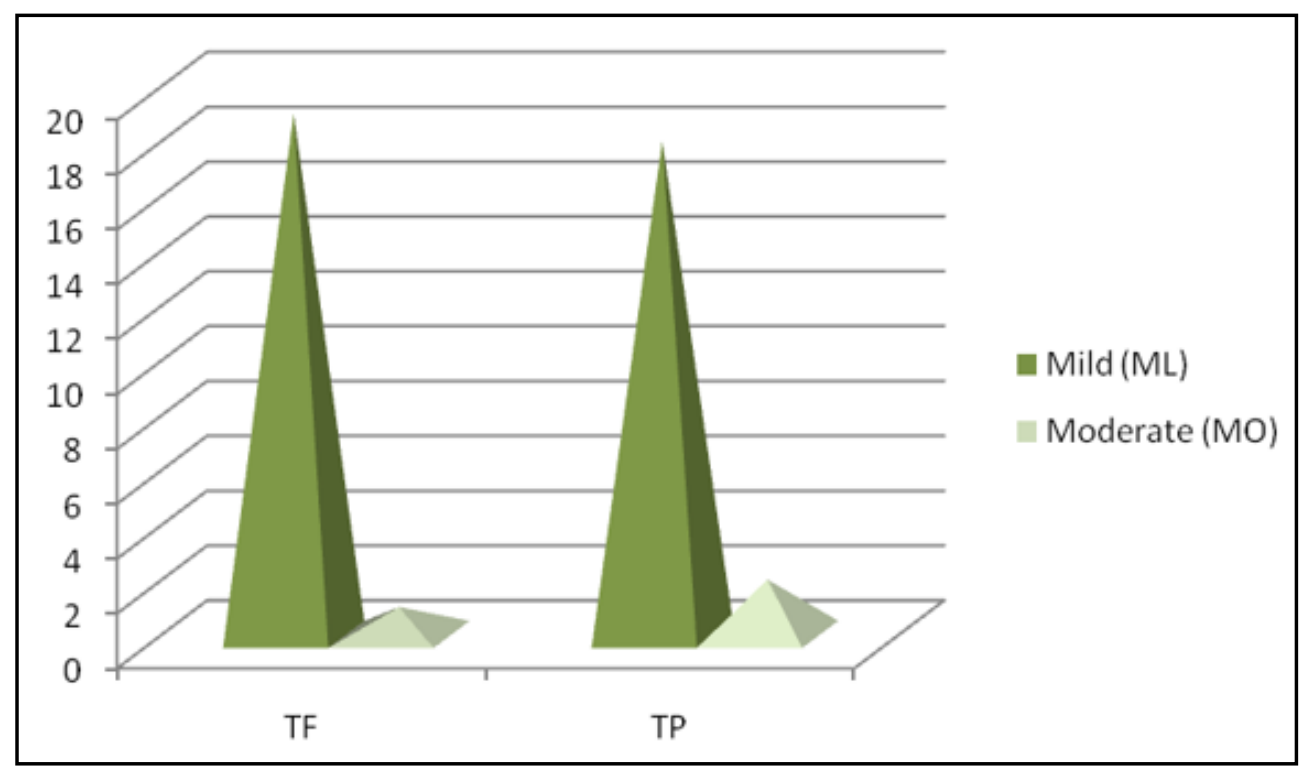

Fig. 2: Distribution of hearing loss among two groups

of symptoms was not statistically significant $(\mathrm{p}=0.8003)$ between two groups. (Table III)

In TF group, 19 (95\%) patients had mild hearing loss and $1(5 \%)$ patient had moderate hearing loss. In TP group, $18(90 \%)$ patients had mild hearing loss and 2 (10\%) patient had moderate hearing loss. Hearing loss of two groups was almost equally distributed $(\mathrm{p}=0.5483)$. (Fig.2)

Distribution of Size of perforation of two groups was not statistically significant $(p=0.7411$ ). (Table IV)

Mean pre-op AC threshold difference of two groups was not statistically significant $(\mathrm{p}=0.3646)$. Mean preop AB gap difference of two groups was not statistically significant $(p=0.5641)$. $($ Table $V)$

Mean post-op AB gap difference of two groups was statistically significant $(p=0.0013)$, that is mean post op
AB gap was less in TF group than in TP group. Mean post-op AC threshold difference of two groups was statistically significant $(p=0.0075$.) Mean post op AC threshold with temporalis fascia was better than tragal perichondrium. (Table VI)

Mean audiological gain difference of two groups was statistically significant $(p=0.0294)$, that is mean audiological gain is better in TF group than in TP group . (Fig. 3)

In both TF and TP group, difference between pre-op and post op AC threshold was statistically significant $(\mathrm{p}<0.001)$.

In both TF and TP group, difference between preop and post op $\mathrm{AB}$ gap was statistically significant $(\mathrm{p}<0.001)$.

Graft uptake rate in TF group and TP group are not

Table IV: Table showing distribution of size of perforation among two groups.

\begin{tabular}{|c|c|c|c|}
\hline \multirow{2}{*}{ SIZE OF PERFORATION } & \multicolumn{3}{|c|}{ GROUP } \\
\cline { 2 - 4 } & TF & TP & TOTAL \\
\hline Central & $14(70 \%)$ & $12(60 \%)$ & $26(65 \%)$ \\
\hline Subtotal & $6(30 \%)$ & $\mathbf{8 ( 4 0 \% )}$ & $14(35 \%)$ \\
\hline TOTAL & 20 & 20 & 40 \\
\hline
\end{tabular}


Table V: Pre-operative Distribution of hearing threshold and AB gap in two groups

\begin{tabular}{|c|c|c|c|c|c|c|}
\hline \multirow{2}{*}{ GROUP } & \multicolumn{3}{|c|}{ PRE-OP AB GAP } & \multicolumn{3}{c|}{ PRE-OP AC THRESHOLD } \\
\cline { 2 - 6 } & MEAN & SD & P VALUE & MEAN & SD & P VALUE \\
\hline TF & 31.9 & 5.1 & \multirow{2}{*}{0.5641} & 30.75 & 5.16 & \multirow{2}{*}{0.3646} \\
\cline { 2 - 3 } TP & 32.8 & 4.66 & & 32.2 & 4.81 & \\
\hline
\end{tabular}

Table VI : Post-operative Distribution of hearing threshold and AB gap in two groups

\begin{tabular}{|c|c|c|c|c|c|c|}
\hline \multirow{2}{*}{ GROUP } & \multicolumn{3}{|c|}{ POST OP AB GAP } & \multicolumn{2}{c|}{ POST OP AC THRESHOLD } \\
\cline { 2 - 5 } & MEAN & SD & P VALUE & MEAN & SD & P VALUE \\
\hline TF & 13 & 6.34 & \multirow{2}{*}{0.0013} & 14.15 & 8.05 & 0.0075 \\
\cline { 2 - 3 } TP & 19 & 6.22 & & 20.95 & 7.14 & \\
\hline
\end{tabular}

statistically significant, $\mathrm{p}=0.6325$ (Fig. 4).

The Graft uptake success rate was $88.46 \%$ in central perforation and $85.71 \%$ in subtotal perforation. Association between graft uptake with respect to size of perforation (Fig. 5) was not statistically significant (p value $=0.802$ )

The post-op complications are illustrated in Fig. 6.

\section{Discussion}

The mean age was 32.28 years $( \pm 10.27$ years $)$. Similar findings were noted in the study of Singh et $\mathrm{al}^{11}$ in which the mean age was 28.9 years and in the study of Dornhoffer ${ }^{12}$ in which the mean age was 28 years. Varshney and Nangia observed similar finding that the number of cases in the16-25 years age group was $(51.3 \%)$, and this formed the largest group in their

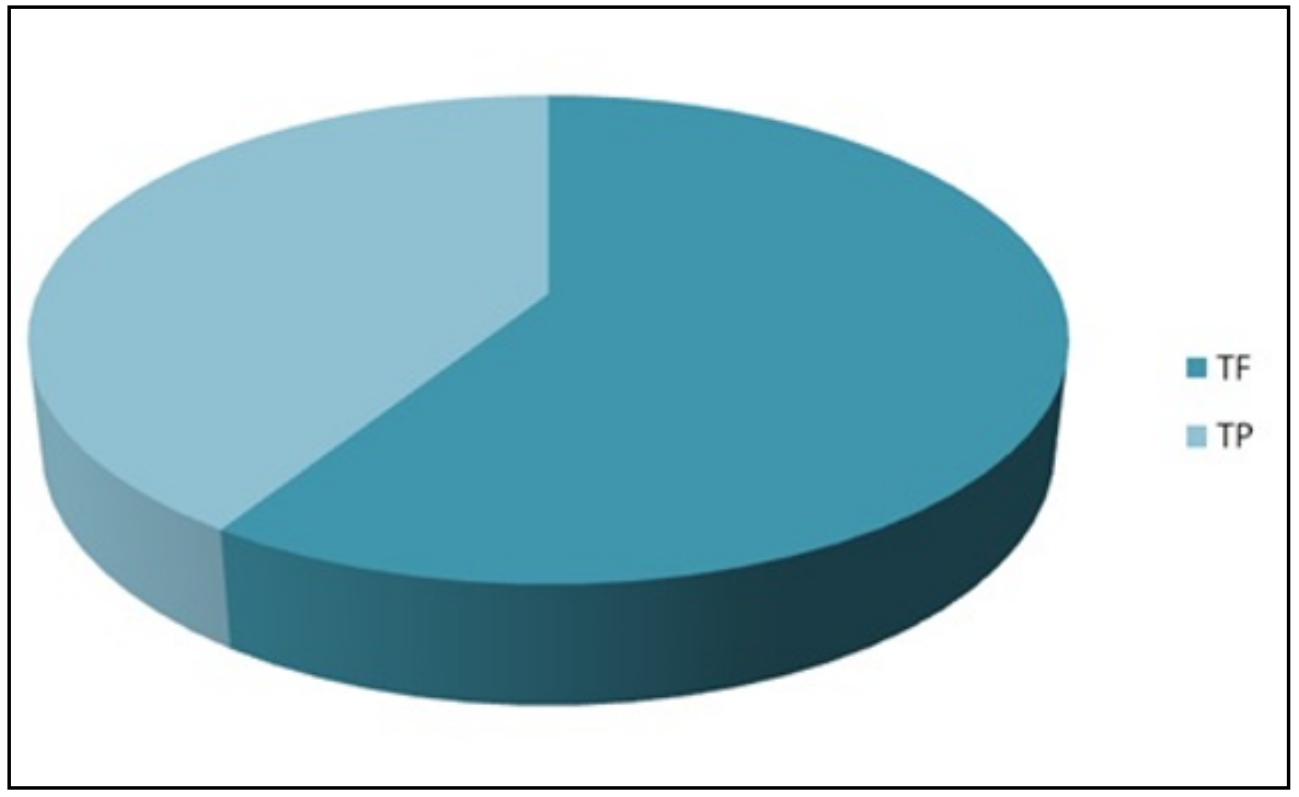

Fig. 3 : Mean audiological gain in 2 groups. 


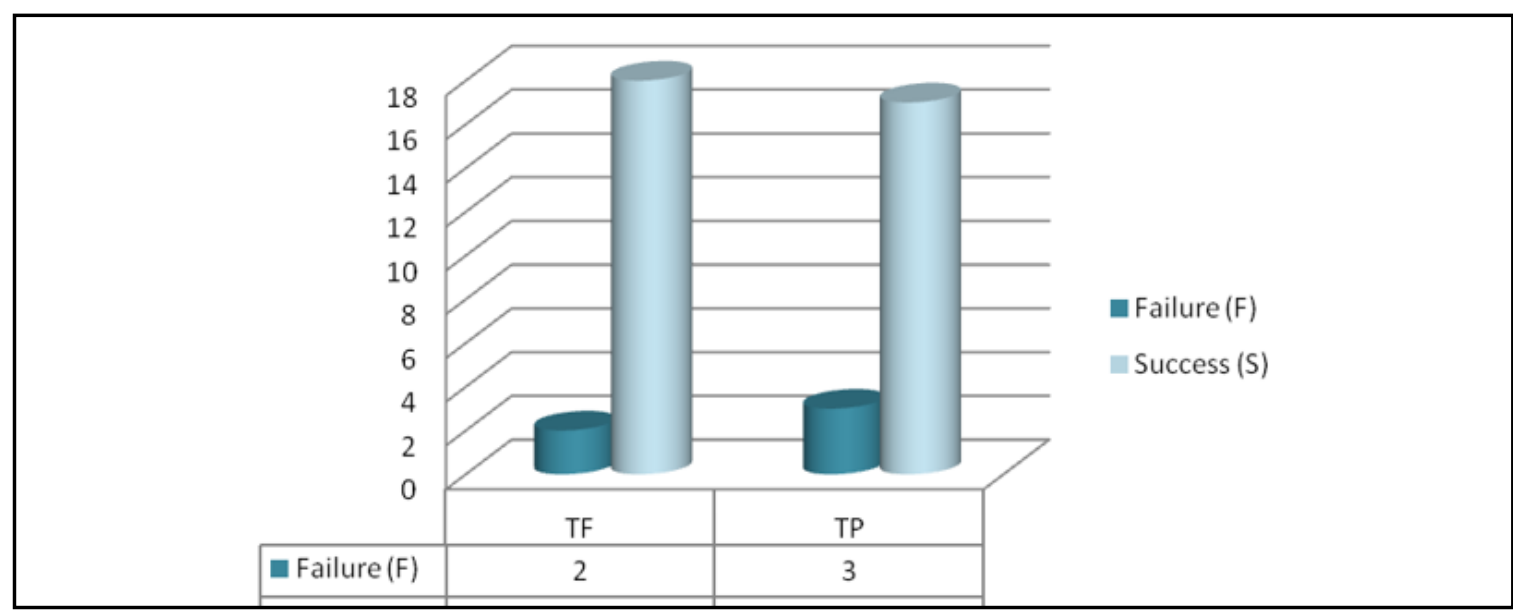

Fig. 4: Graft uptake distribution in 2 groups.

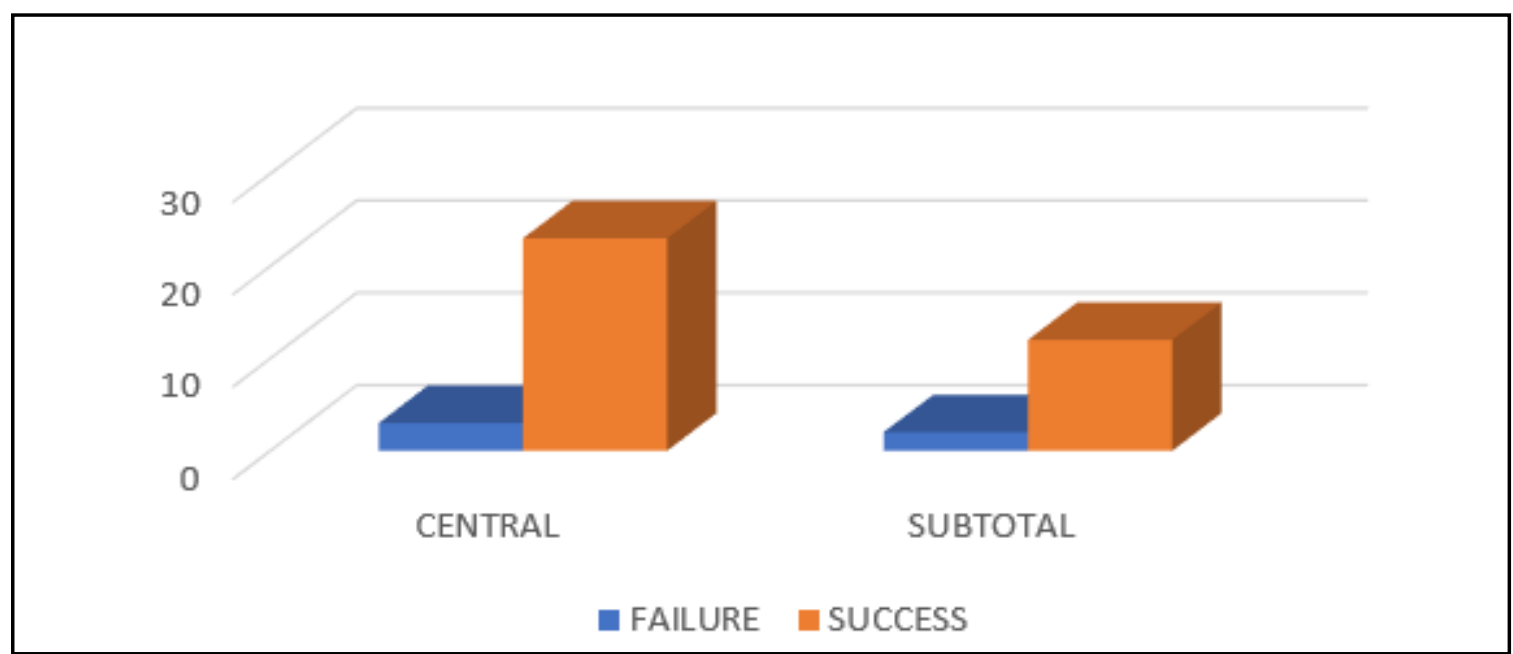

Fig. 5: Graft uptake in respect to size of perforation.

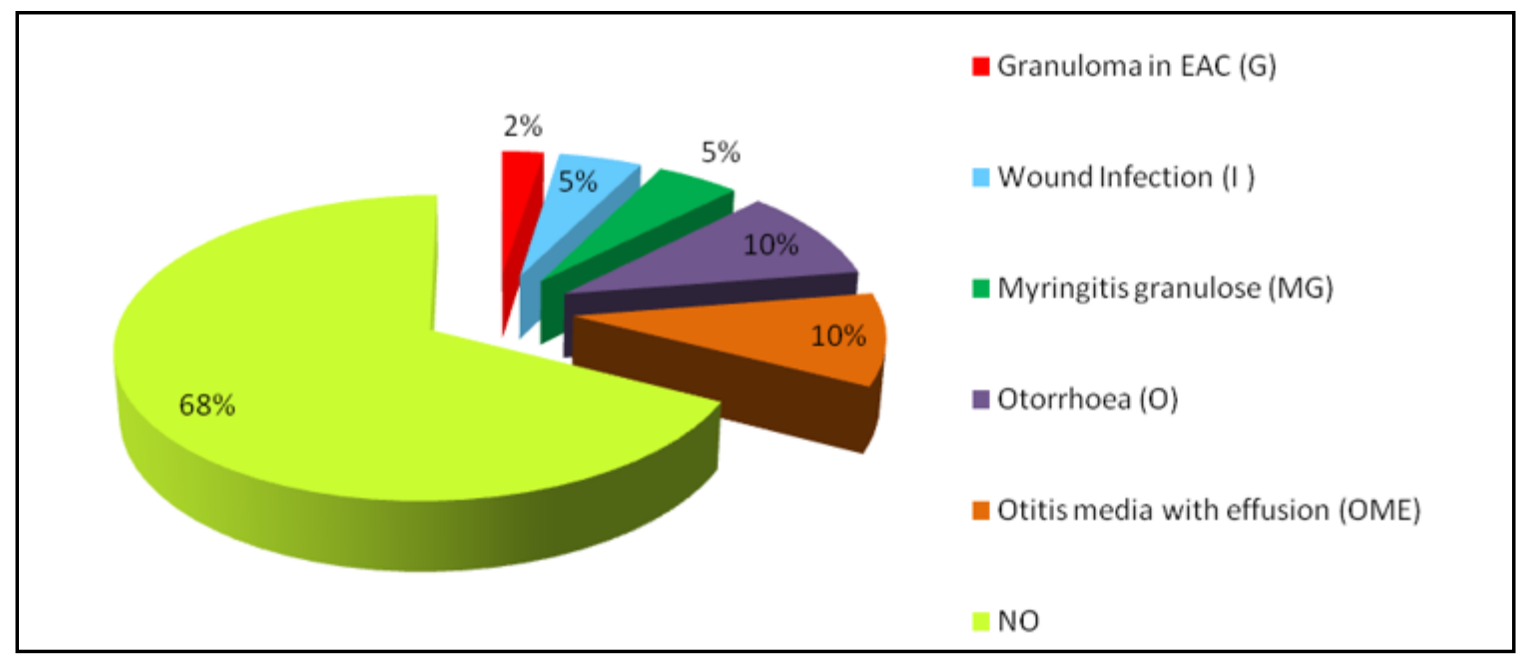

Fig. 6 : Post-op Complications 
study. ${ }^{13}$ Raine and Singh in a retrospective analysis of 114 tympanoplasties in children in the age group of 7 to 16 demonstrated a significant higher rate of failure between 8 and 12 years. The probable explanation of high incidence of failure in younger children is due to increased incidence of upper respiratory tract infection and immature Eustachian tube function. They advocate deferring surgery till 12 years for achieving better results. ${ }^{14}$

Male to female ratio in this study was 1.2:1. Sex ratio did not have any statistically significant difference between the two groups.

Palva et al achieved success rate of $96 \%$ in their study of 165 cases of myringoplasties, which was carried out only when the ear was dry for at least 3 months. ${ }^{16}$ Gibb and Chang, in their study of 206 cases of underlay myringoplasty, found the uptake rate of $91.4 \%$ for dry ear and $80.9 \%$ for wet ear. ${ }^{17}$ The state of middle ear at the time of operation influences surgical outcome and long term result of myringoplasty in adult and children with wet ears having higher rate of reperforation. ${ }^{18}$ In our study of 40 cases of tympanoplasty all cases had dry ear preoperatively at least for 6 weeks. The overall graft uptake rate was $87.5 \%$.

Shrestha and Sinha, found preoperative A-B gap of around $30 \mathrm{~dB}$ in $76 \%$ of the patients. ${ }^{19}$ In another study by Shaikh et al, showed mean pre-operative air conduction of $40 \mathrm{~dB}$ and A-B gap of around $25 \mathrm{~dB} \cdot{ }^{15} \mathrm{In}$ our study, the mean pre-op AC threshold was $30.75 \mathrm{~dB}$ in TF group and $32.2 \mathrm{~dB}$ in TP group.

In our study $65 \%$ had central and $35 \%$ subtotal perforation. Distribution of size of perforation was not significant among the two groups in our study. In the comparative study by Awan et al $76.7 \%$ cases had medium sized perforation. ${ }^{20}$ Hussain et al had patients with small or medium size perforation in $75 \%$ cases and large perforation in $25 \%$ cases. ${ }^{21}$ Similar selection criteria regarding the size of perforation, as were used in the studies of Indorewala ${ }^{22}$ and Roychaudhuri ${ }^{23}$ to have a consistency in the outcome and to avoid bias in the analysis of the results of surgery.

In our study $87.5 \%$ patients show improvement in hearing, $12.5 \%$ shows no improvement. In TF group $90 \%$ patients show improvement in hearing and in $\mathrm{TP}$ group $85 \%$ patients show improvement in hearing. Dabholkar et $\mathrm{al}^{24}$ reported hearing result in total 50 patients, temporalis fascia group improved hearing in $76 \%$ while tragal perichondrium group achieved $75 \%$ hearing gain. Umar et al showed post-operative improvement in hearing in $87.06 \%$ of patients. ${ }^{25}$ In his study $12.94 \%$ patients failed to show any improvement of A-B gap.

In our study Group TF, the mean audiological gain (mean \pm SD) of patients was $17.7500 \pm 8.0516 \mathrm{~dB}$. In Group TP, the mean audio logical gain (mean \pm SD) of patients was $12.3000 \pm 7.1532 \mathrm{~dB}$. Patil et al reported that, mean gain in $\mathrm{ABG}$ was not significantly different between the different graft materials used in tympanoplasty. ${ }^{26}$ The mean gain for temporalis fascia was $9.36 \mathrm{~dB}$, tragal perichondrium was $10.92 \mathrm{~dB}$. Similar findings were noted by Dornhoffer, where in it was $10.2 \mathrm{~dB}$ for tragal perichondrium.12 Indorewala noted a higher gain of $17 \mathrm{~dB}$ for temporalis fascia. ${ }^{23}$ Singh et al achieved mean gain of $9.3 \mathrm{~dB}$ for temporalis fascia, and $8.5 \mathrm{~dB}$ for tragal perichondrium, which is lesser than our study. ${ }^{11}$

In our study $87.5 \%(n=35)$ patients had overall successful result in graft uptake. The overall success rate of type 1 tympanoplasty using temporalis fascia were $90 \%(\mathrm{n}=18)$ and using tragal perichondrium were $85 \%(\mathrm{n}=17)$ respectively. $12.5 \%(\mathrm{n}=5)$ patients were marked as failure cases during post-operative follow up period. The overall failure rate of type 1 tympanoplasty using temporalis fascia were $10 \%(\mathrm{n}=2)$ and with tragal perichondrium were $15 \%(n=3)$ respectively. Palva and Virtaen in their study of 172 cases, found a number of successfully repaired tympanic membrane of 153 $(89 \%){ }^{27}$

Gibb and Chang in their study of 206 cases of myringoplasty employing the underlay technique with temporalis fascia reported a graft take rate of $89.3 \% .{ }^{17}$ Our results are comparable with study of Strahan et al, in which take-up rate of $87.5 \%$ was achieved using temporalis fascia and $86 \%$ by tragal perichondrium by underlay technique. ${ }^{28}$ Eviatar noted that graft take rate with tragal perichondrium by underlay technique was $88 \%$ at the end of 1 year follow-up. ${ }^{29}$ Dornhoffer achieved graft uptake success rate of $85 \%$ using tragal perichondrium by underlay technique. ${ }^{12}$ Rizer achieved a 
success rate of $88.8 \%$ using temporalis fascia by underlay technique. ${ }^{30}$ Dabholkar et al compared temporalis fascia with Tragal Perichondrium in underlay tympanoplasty and achieved a graft success rate of $84 \%$ for Temporalis fascia and $80 \%$ for tragal perichondrium. ${ }^{24}$

\section{Conclusion}

From the present study we may conclude that temporalis fascia, tragal perichondrium free grafts provide viable autograft material for tympanoplasty. They achieve comparable and excellent graft up take of $90 \%$ in temporalis fascia group and $85 \%$ in tragal perichondrium group. They achieve good hearing restoration but the improvement in hearing or audiological gain is better in temporalis fascia graft than in tragal perichondrium graft. Size of the perforation doesn't significantly influence the success rate of tympanoplasty. Normal translucent appearance of neotympanic membrane in the postoperative period was seen with temporalis fascia while with tragal perichondrium, the neotympanic membrane was whitish, thicker, and translucent to opaque. Thus with all the things we come to the conclusion that the graft uptake rate of type 1 tympanoplasty is not influenced by graft material (temporalis fascia and tragal perichondrium) but the hearing improvement depends upon the graft material and it is better with temporalis fascia than tragal perichondrium.

\section{References}

1. Berthold E. Uber Myringoplastic. Med-chir centralb. 1879; 14: 195-207

2. Goodhill V. Articulated polyethylene prosthesis with perichondrial graft in stapedectomy. Rev Laryngol. (Bordeaux) $1951 ; 82: 305-20$

3. Linde RE. The cartilage-perichondrium graft in the treatment of posterior tympanic membrane retraction pockets. Laryngoscope $1973 ; 83: 747-53$

4. Tabb HG. Closure of perforations of the tympanic membrane by vein grafts: a preliminary report of 20cases. Laryngoscope 1960; 70:271-86

5. Storrs L. Myringoplasty with the use of Fascia Grafts. Arch Otolaryngol. 1961; 74:45-9

6. Yetiser S, Tosun F, Satar B. Revision myringoplastywith solvent-dehydrated human dura mater. Otolaryngol Head Neck Surg. 2001;124(5):518-21

7. Heermann J, Heermann H, Kopstein E. Fascia and cartilage palisade tympanoplasty. Arch Otolaryngol. 1970; 91:228-41

8. Couloigner V, Baculard F, El Bakkouri W, Viala P, Francois $\mathrm{M}$, Narcy $\mathrm{P}$ et al. Inlay butterfly cartilage tympanoplasty in children. Otol Neurotol. 2005; 26:247-51

9. Gerber MJ, Mason JC, Lambert PR. Hearing results after primary cartilage tympanoplasty. Laryngoscope 2000;110:1994-9

10. Adkins WY. Composite autograft for tympanoplasty and tympanomastoid surgery. Laryngoscope 1990; 100:244-7

11. Singh BJ, Sengupta A, Das SK, Ghosh D, Basak B. Acomparative study of different graft materials used in myringoplasty. Indian J Otolaryngol Head Neck Surg. 2009; 61:131-4

12. Dornhoffer JL. Hearing results with cartilage tympanoplasty. Laryngoscope 1997; 107:1094-9

13. 13.Varshney S, Nangia A. Ossicular status in chronic suppurative otitis media in adults. Indian J Otolaryngol Head Neck Surg. 2010; 62(4):421-6

14. Raine $\mathrm{CH}$ and Singh SD. Tympanoplasty in Children: A Review of 114 Cases. Journal of Laryngol Otol. 1983; 97:217-21

15. Shaikh AA ,Onali.MAS, Shaikh MS, Rafi T. Outcome of Tympanoplasty type I by Underlay Technique. JLUMHS 2009; 8(1): 80-4

16. Palva T. Surgical treatment of chronic ear disease 1. Myringoplasty and tympanoplasty. Acta Otolaryngol. (Stockh) 1987; 104(3-4): 279-84

17. Gibb AG, Chang SK. Myringoplasty (A review of 365 operations). J Laryngol Otol. 1982; 96:915-30

18. Gersdoff M, Grain P, Decat M, Jugantegui M. Myringoplasty: Long term result in adult and children. .Am J Otol. 1995; 16(4):532-5

19. Shrestha S, Sinha BK. Hearing results after Myringoplasty. Kathmandu Medical College University Journal 2006; 4(16): 455-9

20. Awan Z, Bashir H, Hussain A. Myringoplasty: A comparative study of different graft materials and various surgical techniques. Ann. Pak. Inst. Med. Sci. 2008;4(4): 209-11

21. Hussain A, Yousaf N, Khan AR. Outcome of myringoplasty. J Pak Med Assoc 2004; 18:695-8

22. Indorewala S. Dimensional stability of free fascia grafts: Clinical application. Laryngoscope 2005;115:278-82

23. Roychaudhuri BK. 3-flap tympanoplasty-A simple and sure success technique. Indian J Otolaryngol Head Neck Surg. 2004; 56:196-200

24. Dabholkar JP, Vora K, Sikdar A. Comparative study of underlay Tympanoplasty with temporalis fascia and tragal perichondrium. Indian J Otolaryngol Head Neck Surg. 2007; 59(2):116-9

25. Umar AS, Ahmed J. Anatomical and functional outcome 
following type 1 tympanoplasty in chronic tubotympanic SOM. Military Hospital Rawalpindi, March, 2008; Issue-1

26. Patil K, Baisakhiya N, Deshmukh PT. Evaluation of different graft materials in type1 tympanoplasty. Indian J Otology 2014; 20(3):106-14

27. Palva T, Virtanen H. Pitfalls in myringoplasty. Acta Otolaryngology 1982; 93:441-6
28. Strahan RW, Acquarelli M, Ward PH, Jafek B. Tympanic membrane grafting. Analysis of materials and techniques. Ann Otol Rhinol Laryngol. 1971; 80:854-60

29. Eviatar A. Tragal perichondrium and cartilage in reconstructive ear surgery. Laryngoscope 1978; 88(Suppl) 11:1-23

30. Rizer FM. Overlay versus underlay tympanoplasty. Part II: The study. Laryngoscope 1997; 107:26-36. 